\title{
O USO DA TOPOGRAFIA PARA AUXILIO DE RECUPERAÇÃO DE UMA ÁREA DEGRADADA.
}

\author{
Luiz Waldemar de Oliveira ${ }^{1}$
}

\author{
Andre Gonçalves Vieira ${ }^{2}$
}

\section{Marcelo Wendeborn Miranda de Oliveira $^{3}$}

\begin{abstract}
RESUMO
Este estudo teve como objetivo caracterizar a importância da topografia no ramo Ambiental, principalmente na área florestal, apresentando informações primordiais que essa atividade pode oferecer para a realização de Recuperações de Áreas Degradadas. Os grandes impactos sociais e ambientais vêm sendo causado pela expansão urbana e a falta de estudos estruturais. Com isso fica claro que é necessário o uso racional e o manejo sustentável dos recursos naturais renováveis adotando medidas de recuperação das áreas degradadas, exploradas inadequadamente. Sendo assim foi escolhido o levantamento planialtimétrico cadastral para o levantamento dos dados. Além de caracterizar o uso e a ocupação do solo, foram coletados pontos por toda a área de estudo, para que fosse possível identificar a localização das cercas existentes, áreas úmidas, corpos d'água, regiões com vegetação nativa, erosões, e também pontos para caracterizar a altimetria local. Posteriormente criou-se a planta contendo carimbo, legenda, planta de situação e foi terminado o mapa onde o mesmo contem todas as informações referentes ao projeto. Com o apoio do relatório fotográfico e o mapa elaborado, comprovou-se que a instituição está totalmente irregular diante do que preconiza a Nova Legislação Florestal vigente, de 2012. Ficando evidente a importância da topografia, na tomada de decisões, quando da elaboração de projetos de recuperação de áreas degradadas.
\end{abstract}

PALAVRAS-CHAVE: Levantamento Planimétrico, Exploração intensiva, Destruição.

\section{USE OF SURVEYING TO AID RECOVERY OF A DEGRADED AREA.}

\section{ABSTRACT}

\footnotetext{
${ }^{1}$ Biólogo, Me. Universidade do Oeste Paulista/UNOESTE. E-mail. oliveira@unoeste.br

${ }^{2}$ Biólogo, Licenciatura/Bacharelado

E-mail. dre goncalves@hotmail.com

${ }^{3}$ Biólogo, Alta Sorocabana/APTA, Bolsista FAPESP.

E-mail.marcelo_wendeborn@hotmail.com
} 
This study aimed to characterize the importance of topography in the Environmental sector, mainly in forestry, presenting critical information that this activity may offer to perform Recovery of Degraded Areas. The great social and environmental impacts have been caused by urban sprawl and the lack of structural studies. Thus it is clear that the rational use and sustainable management of renewable natural resources by adopting recovery of degraded areas measured, inadequately explored is required. Thus the cadastral survey planialtimetric was chosen to gather data. Besides characterizing the use and occupation of land, points were collected throughout the study area, it was possible to identify the location of existing fencing, wetlands, water bodies, areas with native vegetation, erosion, and also points to characterize the local altimetry. Subsequently created the plant containing Stamp, legend, and the situation was terminated plan map where it contains all the information related to the project. With the support of the photographic report and map prepared, it was shown that the institution is totally irregular before calling for the current New Forest Law of 2012 Staying clear the importance of topography, in making decisions when drafting projects recovery of degraded areas.

KEY-WORDS: Planimetric Survey, intensive exploitation, Destruction.

\section{EL USO DE LA TOPOGRAFÍA AYUDA A LA RECUPERACIÓN DE UNA ZONA DEGRADADA.}

\section{RESUMEN}

Este estudio tuvo como objetivo caracterizar la importancia de la topografía en el sector del medio ambiente, principalmente en el sector forestal, la presentación de la información crítica que esta actividad puede ofrecer para realizar la recuperación de áreas degradadas. Los grandes impactos sociales y ambientales han sido causados por la expansión urbana y la falta de estudios estructurales. Por lo tanto, es evidente que se requiere el uso racional y el manejo sostenible de los recursos naturales renovables mediante la adopción de la recuperación de áreas degradadas medidos, insuficientemente explorado. Así, la encuesta planialtimétrico catastral fue elegido para recopilar datos. Además de caracterizar el uso y ocupación de la tierra, se recogieron los puntos a lo largo del área de estudio, fue posible identificar la ubicación de vallas existentes, humedales, cuerpos de agua, áreas con vegetación nativa, la erosión, así como puntos para caracterizar la altimetría local. Posteriormente creó la planta que contiene sello, la leyenda y la situación se terminó mapa plan donde se contiene toda la información relacionada con el proyecto. Con el apoyo del reportaje fotográfico y el mapa elaborado, se demostró que la institución es totalmente irregular antes de llamar a la corriente Nueva Ley Forestal de 2012 Alojarse en claro la importancia de la topografía, en la toma de decisiones en la elaboración de proyectos recuperación de áreas degradadas.

PALABRAS-CLAVE: Levantamiento planimétrico, la explotación intensiva, la destrucción.

\section{INTRODUÇÃO}

A recuperação de áreas degradadas pode ser conceituada como um conjunto de ações idealizadoras e executadas por especialistas das mais diferentes áreas de conhecimento humano e da engenharia, que visam a proporcionar o restabelecimento 
das condições de equilíbrio e sustentabilidade existentes anteriormente em um sistema natural (TESTONI, 2010).

Segundo Reis, Zambonin e Nakazono (1999), uma determinada área que sofreu impacto de forma a impedir ou diminuir drasticamente sua capacidade de retornar ao estado original, por intermédio de seus meios naturais, é denominado área degradada. A capacidade de regeneração natural chama-se resiliência ambiental. Por outro lado, Kageyama e Reis (1994) consideram área degradada àquela que, após distúrbio, teve eliminado seus meios de regeneração natural, não sendo, portanto, capaz de se regenerar sem a interferência antrópica.

Dentre os principais fatores relacionados com o aumento da degradação ambiental estão as frequentes alterações não planejadas no uso do solo (GUERRA \& CUNHA, 1996; PRUSKI et al., 2006).

Segundo Bertoni \& Lombardi Neto (1990) o uso inadequado do solo desencadeia a erosão antrópica ou acelerada devido às atividades agrícolas ou urbanas, que aceleram e intensificam os processos erosivos devido às condições induzidas ou modificados pelo homem ao solo (BERTONI \& LOMBARDI NETO 1990; GRILO \& ENAMI 2008). Existem casos em que a natureza não apresenta condições de se recompor, ou a recuperação vegetal se apresenta muito lenta, é necessária a intervenção técnica para permitir que processos de sucessão natural possam ser realizados (REDENTE et al., 1993).

Do ponto de vista qualitativo, a proteção dos solos e os recursos hídricos depende fundamentalmente de medidas disciplinadoras do uso do solo em bacias, para diagnóstico e avaliação da degradação ambiental gerada, tem-se utilizado a bacia hidrográfica como uma unidade de planejamento, para o uso e exploração dos recursos naturais (PISSARRA, 1998; PISSARRA et al., 2004).

As características geomorfológicas de uma bacia hidrográfica como a rede de drenagem, forma, área, relevo e solos aliados ao tipo de cobertura vegetal influenciam o comportamento hidrológico de uma bacia hidrográfica (LIMA, 1986; GUERRA e CUNHA, 1996).

Para caracterizar os processos de degradação ambiental, devem-se analisar os elementos do meio físico que participam desse processo, em grandes áreas as 
informações requer a utilização de sistemas nos quais seja possível integrar os dados (CASTRO, 1992; RANIERI, 1996).

Nesse contexto, a topografia, ocupa posição primordial, deve ser um item indispensável à tomada de decisões para a realização de Recuperação de Áreas Degradadas, haja vista o que determina a Instrução Normativa IN-16 da Fundação do Meio Ambiente (Fatma): no processo de Licenciamento Ambiental para a Recuperação de Áreas Degradadas, deverá ser apresentada a planta planialtimétrica da área do plano ou projeto, com hidrografia, Áreas de Preservação Permanente (APP) e detalhe do plano/projeto, em UTM ou coordenada geográfica com a informação do Datum de origem (FUNDAÇÃO DO MEIO AMBIENTE, 2013). Para Parada (1992), uma simples observação "in loco" do terreno ou uma área em questão não permite uma prévia para a construção direta, já que se realizada por tentativas estará certamente sujeita a erros gravíssimos. A topografia consiste no conhecimento dos instrumentos e métodos os quais têm por finalidade reuzir os erros de observação "in loco" e determinar o contorno, dimensão e posição relativa de uma porção limitada da superfície terrestre, sem considerar a curvatura resultante da esfericidade terrestre (LOCH, 2000).

Testoni (2010) ressalta a incumbência em um levantamento de proceder a todas as operações necessárias para alcançar os objetivos da topografia, como, a medição de ângulos e distâncias e a execução dos cálculos e desenhos indispensáveis para representar, fielmente em planta, os elementos colhidos no terreno.

No campo da engenharia, a planta topográfica é a primeira e insubstituível peça de estudo, nenhum projeto de construção de obras civis, militares e/ou ambientais pode dispensar o prévio levantamento topográfico ( $\mathrm{LOCH}, 2000$; TESTONI, 2010).

Borges (2010) destaca o levantamento topográfico como representante, no papel, a configurar um terreno com as suas características e benfeitorias que estão em sua superfície, permitindo a representação, em planta, dos limites da propriedade, dos detalhes que estão em seu interior. 
A estação total obtém as cotas do terreno e armazena, em seu computador interno, variados levantamentos, podendo ser de diferentes locais. Além de economizar tempo, esses dados podem ser diretamente enviados ao computador do profissional, através de softwares específicos, como o AutoCad (MASSITA, 2009; SILVA, 2009).

Stodulski (2006) classifica os levantamentos topográficos para cada finalidade, método de levantamento e característica de terreno existindo uma forma mais apropriada de se realizar a coleta dos dados, sendo o levantamento topográfico planimétrico (ou Perimétrico); levantamento topográfico altimétrico (ou Nivelamento); levantamento topográfico planialtimétrico.

Erba (2005) recomenta o uso de poligonal aberta, poligonal fechada e poligonal apoiada, a irradiação para amarrar pontos de detalhes a um sistema de referência por meio da medição de uma direção e uma distância como auxilio para poligonal.

Segundo Braga et al., (2004), existem os níveis de detalhamento sendo o levantamento por Caminhamento e o levantamento Inicial. O levantamento Cadastral acontece posterior ao levantamento das áreas, limites e perímetro, e faz a locação em coordenadas precisas (STODULSKI, 2006).

Dentro deste contexto, o objetivo deste trabalho foi caracterizar a importância da topografia no ramo Ambiental, principalmente na área florestal, apresentando informações primordiais que essa atividade pode oferecer para a realização de Recuperações de Áreas Degradadas.

\section{DESENVOLVIMENTO}

\subsection{Material e método}

O presente estudo foi realizado no município de Presidente Prudente, município este localizado no interior do estado de São Paulo, estando a $558 \mathrm{Km}$ de distancia da capital, a área utilizada para a realização deste trabalho se encontra na 
Volume 10, Número 2, 2014

Bacias Hidrográficas, Planejamento e Gestão dos Recursos Hídricos

propriedade pertencente à Escola Técnica Prof. Dr. Antônio Eufrásio de Toledo ETEC Presidente Prudente, precisamente, a área está localizada nas coordenadas geográficas de 22K 461.346,10/7.547.391,12 (WSG 84), conforme (Figura 1). O município possui uma temperatura média anual de $21,6^{\circ} \mathrm{C}$ e na vegetação do município predomina uma formação arbórea esparsa.

\section{FIGURA 1 - Área da realização do levantamento topográfico}

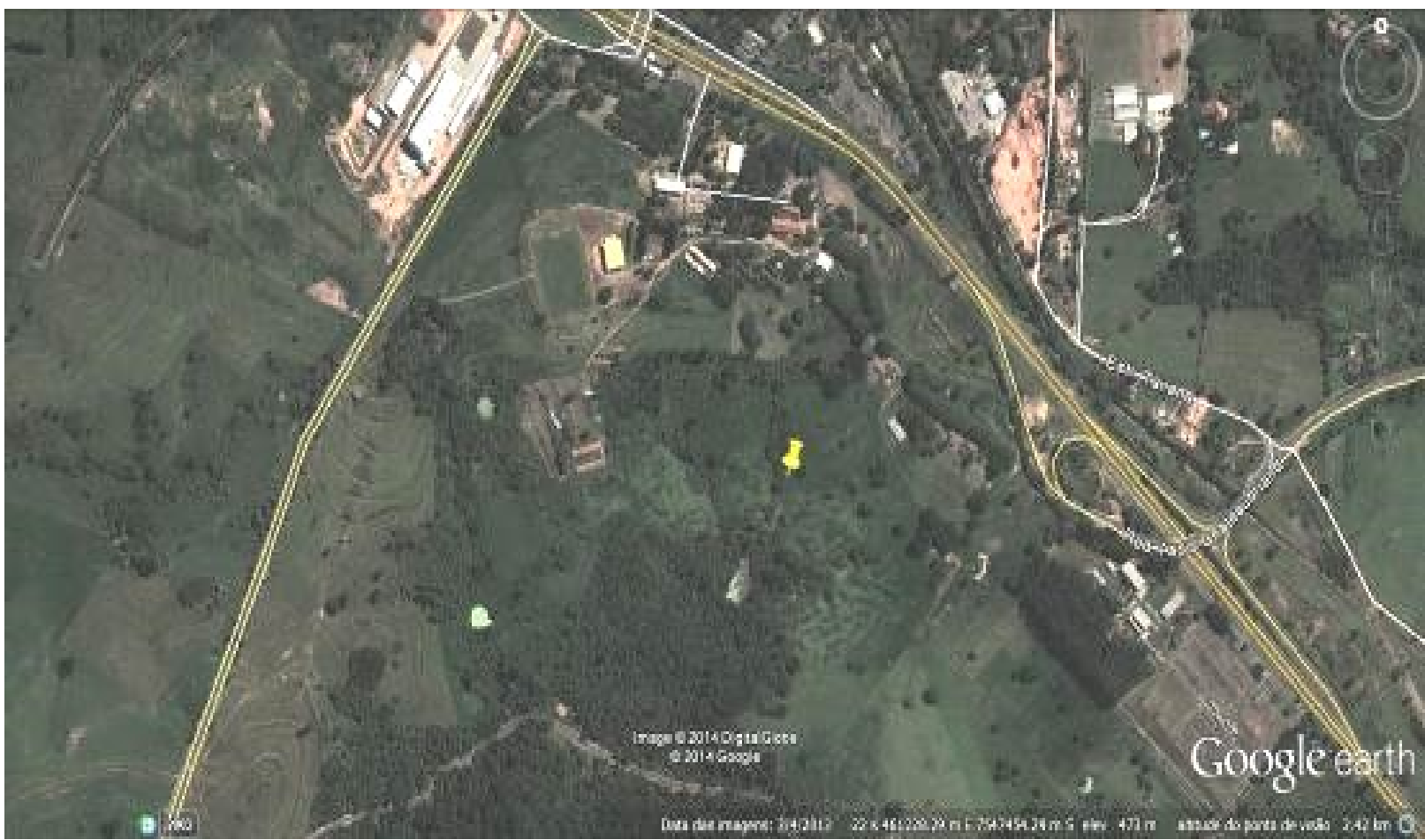

Fonte: Google Earth, (2014).

No dia 17 de maio de 2014 foi realizada uma prévia vistoria sobre a referida área de estudo; optando assim pelo levantamento planialtimétrico cadastral. Além de caracterizar o uso e a ocupação do solo, nessa vistoria ficou evidenciado que o imóvel não atende ao disposto na Legislação Florestal vigente. Dessa forma, haverá a necessidade de elaboração de um Licenciamento Ambiental para Recuperação de Áreas Degradadas e Recomposição de Área para Averbação de Reserva Florestal Legal. 
Para desenvolvimento do trabalho foram utilizados alguns equipamentos, que auxiliaram para o desenvolvimento do trabalho proposto, sendo que primeiramente foi definido o tipo de levantamento que iria ser utilizado na área de estudo.

Após a definição do método de levantamento a ser utilizado, foi necessário à utilização dos seguintes equipamentos, uma estação total da marca RUIDE, um tripé, dois bastões e dois prismas. A Estação Total da marca RUIDE que foi utilizado é do modelo RTS 825, com precisão de 5 segundos.

Em visita ao local da realização do estudo, a equipe verificou todo o local e também se analisaram quais eram as reais situações em que se encontrava a área e discutiu as possíveis dificuldades que seriam encontradas na realização do levantamento planialtimétrico cadastral.

Posteriormente as análises críticas foram pré-fixados os pontos da poligonal a ser realizada no dia do levantamento planialtimétrico cadastral.

Para a definição da implantação dos pontos da poligonal, foram observadas algumas diretrizes, como por exemplo, visadas nos pontos de interesse, dificuldade de acesso aos pontos, possibilidade de abertura de picadas, entre outros fatores. Sendo assim, os pontos de poligonal foram definidos e em seguida foram colocados marcos para materialização dos pontos, assim como estacas próximas aos pontos para servirem de localização dos marcos implantados (Figura 2).

FIGURA 2 - Representação de piquete (A) e testemunho (B).
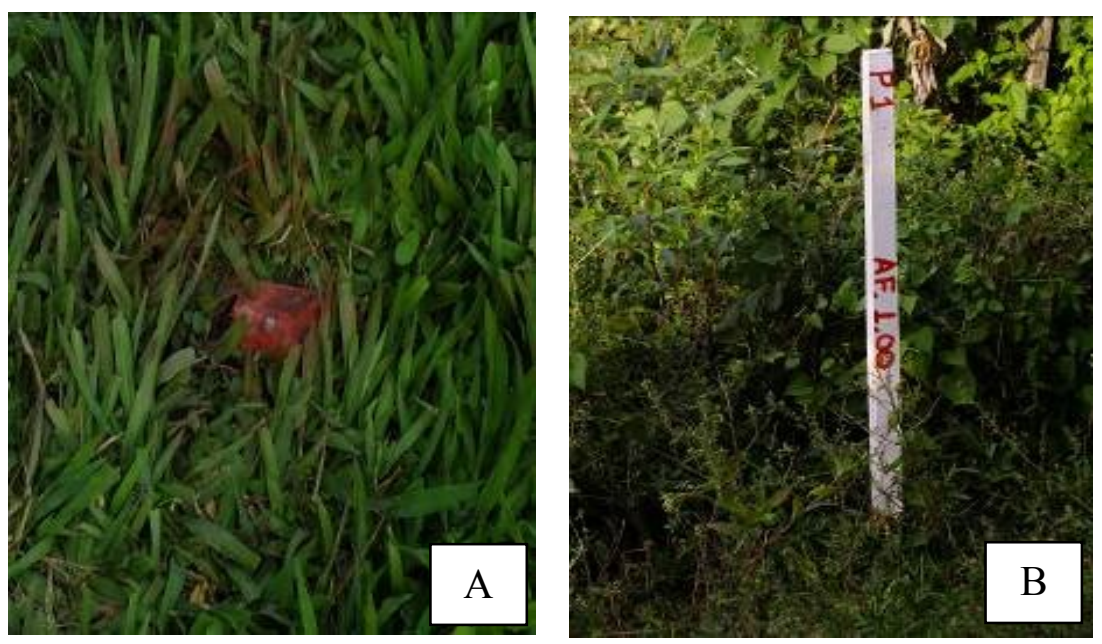

Fonte: Os autores, (2014). 
O piquete (Figura 2A) é fixado no solo com o auxilio de uma marreta, após realizar a fixação do mesmo é inserido no centro do piquete um prego para servir de orientação quando realizada uma leitura de ré ou vante e também para orientação de nivelamento do equipamento topográfico.

A 1/2 metro a 1 metro, é fixado uma estaca que servira de testemunho (Figura 2B) para a localização do piquete.

Se tratando de um levantamento planialtimétrico cadastral, foram predefinidas também as áreas e os pontos a serem cadastrados para que fosse possível realizar o desenvolvimento do trabalho proposto, assim, foram definidos os seguintes pontos, conforme (Quadro 1).

QUADRO 1 - Nomenclatura dos pontos

\begin{tabular}{|c|c|}
\hline Pontos & Nomenclatura \\
\hline Terreno Natural & TN \\
\hline Vegetação Arbórea & VEG \\
\hline Curso d'água & CÁgua \\
\hline Erosão & Erosão \\
\hline Cerca & Cerca \\
\hline Linha de Transmissão de Energia & LT \\
\hline
\end{tabular}

Fonte: Autores, (2014).

Os levantamentos de campo foram realizados nos dias 31 de maio e 07 de junho de 2014 , no horário de inicio as 8:00 horas e termino as 12:00 horas. Para a realização desses levantamentos topográficos na fase inicial de execução das medições, utilizou-se uma equipe de campo composta de quatro pessoas.

Inicialmente, foram determinados os pontos de poligonal, assim como foi definido o nome e numero de cada estação ocupada, e também o sentido de caminhamento anti-horário. 
FIGURA 3 - Levantamento topográfico estação total (A) Levantamento topográfico Prisma (B).



Fonte: Os autores, (2014).

A poligonal foi constituída de apenas três estações, denominadas de P1, P2 e P3 (Figura 3 A - B). A primeira estação ocupada foi a estação P1, deste ponto foi feito uma leitura a "ré" na estação P3 e uma leitura a "vante" na estação P2, e após a realização das leituras descritas anteriormente, foi iniciada a coleta de pontos. O tipo de poligonal escolhido foi a poligonal de classe IP e para a primeira estação ocupada foi determinada uma coordenada arbitrária e assim, as demais estações e também para os pontos coletados, foram sendo calculadas coordenadas.

Foram coletados pontos por toda a área de estudo, para que fosse possível identificar a localização das cercas existentes, áreas úmidas, corpos d'água, regiões com vegetação nativa, erosões, e também pontos para caracterizar a altimetria local, conforme (Figura 04). 
FIGURA 4 - Área assoreada (A), área Erosao (B), área de APP (C) e vegetação rasteira (D).
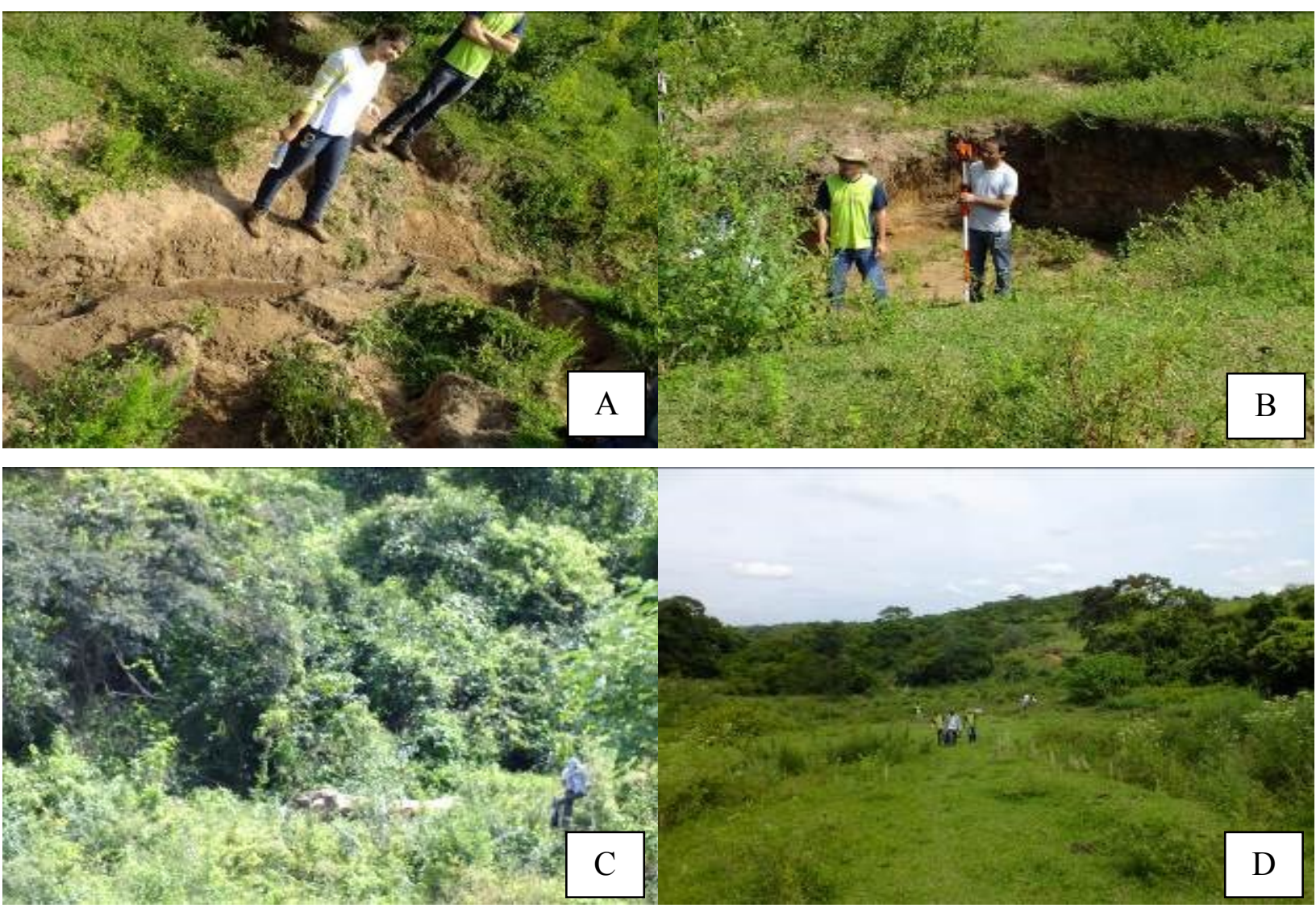

Fonte: Os autores, (2014).

Quando o equipamento estava estalado na estação "P1" foi realizada a irradiação de todos os pontos de interesse que era possível realizar a "visada", sendo os pontos que não fosse possível se ter "visada" foram coletados posteriormente, quando foi realizada a mudança do aparelho para as próximas estações.

$\mathrm{Na}$ segunda fase da execução, para o desenvolvimento dos trabalhos de escritório, quando do descarregamento dos dados levantados por meio da estação total RUIDE, com precisão de $0^{\circ} 00^{\prime} 02^{\prime \prime}$, a etapa seguinte, foi o processamento das informações. 
Após o levantamento topográfico, é necessário que se "descarregue" a estação total, ou seja, é necessário que se extraia os dados obtidos em campo, que estão armazenados dentro da memória do equipamento. Para que seja possível extrair os arquivos coletados em campo é necessário que utilize alguns software's específicos, e no desenvolvimento desse trabalho foi utilizado o software DataGeosis.

Após descarregar as informações obtidas em campo para o software, foi possível ter acessos aos dados e iniciar a elaboração do mapa.

Para realizar a elaboração dos mapas, utilizado um software denominado AutoCad 2014. Após ser gerado através do software DataGeosis, um arquivo em formato .dwg, contendo todos os pontos que foram coletados em campo, iniciou-se o processo de elaboração do mapa.

Primeiramente, foram criadas as Layers, que são denominadas camadas de desenho, ou seja, para cada elemento que foi desenhado foi sendo criada uma camada, como: cerca, curso d'água, linha de transmissão, erosão.

Posteriormente ao processo de criação dos layers, foi definido a cor das respectivas camadas e assim iniciou-se o processo de união dos pontos através de linhas (layers).

Com o avanço do desenvolvimento do desenho foram criadas também as hatches para que fosse possível criar o preenchimento nos locais, como matas e erosões, e posteriormente a esta etapa foi dimensionada a folha para plotagem do desenho. Após a conclusão do mapa, foi necessário realizar a criação de uma folha digital para que pudesse enquadrar o mapa, de imediato foi criada uma no folha que recebeu uma escala de aumento.

Posteriormente criou-se a planta contendo carimbo, legenda, planta de situação e finalização do mapa para plotagem onde o mesmo contem todas as informações referentes ao projeto (Figura 5). 
FIGURA 5 - Mapa finalizado para plotagem

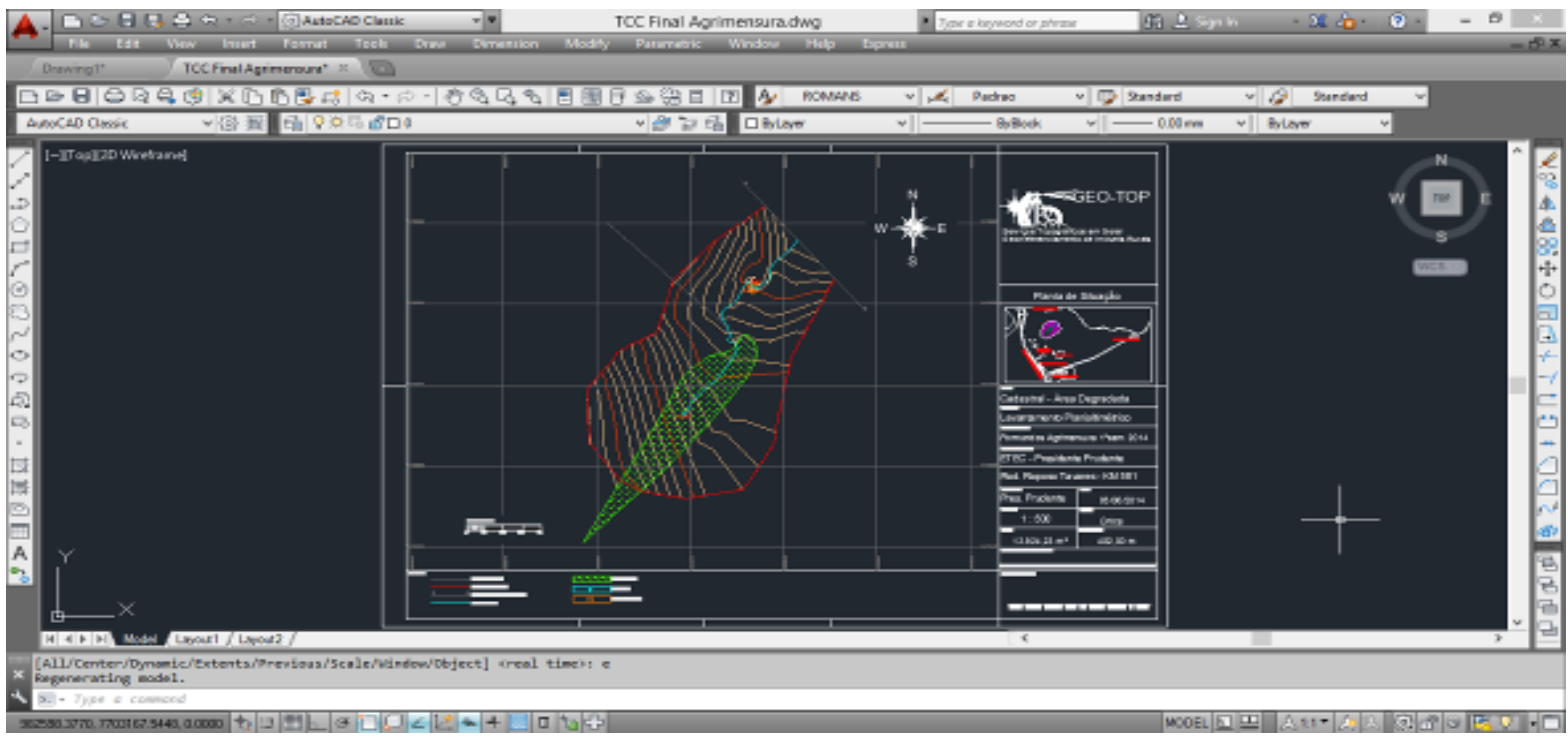

Fonte: Autores, (2014).

\subsection{Resultados e Discussão}

Pela importância e variedade de dados que oferece o mapa elaborado a partir do levantamento planialtimetrico cadastral (Mapa 9), e com o apoio do relatório fotográfico apresentado, comprovou-se que a instituição está totalmente irregular diante do que preconiza a Nova Legislação Florestal vigente, de 2012.

De acordo com a legislação as nascentes d'água, leitos dos rios, córregos ou cursos d'água devem ser constituídas por Áreas de Preservação Permanente respeitando suas metragens a partir do leito de maior vazão ou nascente.

$\mathrm{Na}$ área da propriedade em estudo, observou-se a mudança de um curso natural d'água, realizado por uso inadequado do solo principalmente pela cultura pecuarista causando erosão de grande proporção (FIGURA 4 A - B), ao longo desse curso, a área estava desprovida de vegetação arbórea (FIGURA 4 C), desrespeitando, dessa 
forma, as Áreas de Preservação Permanente, que são áreas protegidas por lei, desde 1965 (Lei 4.777/65), com a função ambiental de preservar os recursos hídricos, a paisagem, a estabilidade geológica, a biodiversidade, o fluxo gênico de fauna e flora; proteger o solo e assegurar o bem-estar das populações humanas.

Da mesma forma, fica claro que a propriedade educacional não possui uma área passível de averbação de Reserva Florestal Legal (20\%), necessária ao uso sustentável dos recursos naturais, à conservação dos processos ecológicos, à conservação da biodiversidade e ao abrigo e proteção da fauna e flora nativas.

A planta topográfica é a primeira e insubstituível peça de estudo um primórdio no campo da engenharia. Baseando-se nas plantas topográficas que estudam os terrenos e se criam projetos, essa ferramenta topográfica torna-se excelência em interpretação das áreas de estudo, indicando características dos danos ambientais causados e os efeitos que estes trazem ao ambiente.

Neste estudo, a falta da mata ciliar na Área de Preservação Permanente (FIGURA 4 C) contribui com a erosão e o assoreamento dos rios devido a falta de proteção do solo.

Os impactos desses conjuntos de danos a sociedade podem ser sentidos diariamente, com o agravamento das secas, das enchentes e com a crescente alta de animais ameaçados de extinção.

Esse tipo de mapeamento tem a função de auxiliar qualquer profissional habilitado, na tomada de decisões, quando da elaboração de projeto que vise à recuperação de áreas degradadas, possibilitando a delimitação da área que deverá ser motivo de recuperação e de reposição (Mapa 4).

É importante ressaltar que essa ferramenta de trabalho não deve ser descartada, pois é uma exigência da Legislação Florestal vigente, e de supra necessidade quando da elaboração de projetos de recuperação de áreas degradadas, e não da recuperação da área propriamente dita.

\section{CONCLUSÃO}


Na Engenharia Florestal, Civil, Agrimensura e Agronomia a topografia ocupa uma posição de destaque, esta ligada diretamente ao planejamento, sua importância nas informações dos dados que são oferecidos junto aos mapeamentos possibilita analisar completamente os dados apurados em campo. É necessária a reconstituição da mata ciliar na Área de Preservação Permanente, devido o assoreamento a erosão da nascente e a falta de proteção do solo.

Com os resultados obtidos evidenciou-se a importância da topografia, na tomada de decisões, quando da elaboração de projetos de recuperação de áreas degradadas.

\section{REFERÊNCIAS}

BERTONI, J.; LOMBARDI NETO, F. Conservação do Solo. 3ª edição. São Paulo: Ícone Editora, 1990.

BORGES, ALBERTO DE CAMPOS. Topografia aplicada à engenharia civil. 2. ed. São Paulo: Editora Blucher, 2010.

BRAGA, F. P. S.; SOUZA FILHO, P. W. M; Sedimentologia e Morfologia da Praia de Macromé de Ajuruteua, Pará: Um Estudo Para Definição de Índices de Sensibilidade Ambiental ao Derramamento de Óleo, 2007, Dissertação (Mestrado) Programa de Pós-Graduação em Geologia e Geoquímica, Universidade Federal do Pará, Belém, 2007.

CASTRO, A. G. Técnicas de sensoriamento remoto e sistemas geográficos de informações no estudo integrado de bacias hidrográficas. 1992. 145 f. Dissertação (Mestrado em Meteorologia) Instituto Nacional de Pesquisas Espaciais, São José dos Campos.1992. Disponível em: http:/urlib.net/sid.inpe.br/íris@1912/2005/07.19.23.35.59 Acesso em: 23 out. 2013.

ERBA, DIEGO ALFONSO (Org.). Topografia para estudantes de arquitetura, engenharia e geologia. São Leopoldo/ RS: Unisinos, 2005.

FUNDAÇÃO DO MEIO AMBIENTE. Recuperação de áreas degradadas. IN-16. Disponível em: <http://www.fatma.sc.gov.br/download/IN_0312/htm/ln_16(Recupera\%E7\%E3o).htm>. Acesso em: 23 out 2013.

GLUFKE, C. Espécies recomendadas para recuperação de áreas degradadas. Porto Alegre: Fundação Zoobotânica do Rio Grande do Sul, 1999.

GRILO, R.C.; ENAMI, L. Gestão de bacias hidrográficas com o uso de modelo preditivo de erosão dos solos e sistemas de informação geográfica. UNAR, Araras, SP, v.2, n.1, p.21-33, 2008.

GUERRA, A. J. T.; CUNHA, S. B. Degradação ambiental. In: CUNHA, S. B. Geomorfologia e meio ambiente. Rio de Janeiro: Bertrand Brasil, 1996. p. 337-379.

KAGEYAMA, P. Y.; REIS, A. Área de vegetación secundaria en el valle de Itajaí, Santa Catarina, Brasil. Perspectivas para su ordenación y conservación. Recursos Genéticos Forestales, v. 21, p. 37-39, 1994. 
LIMA, W. P. Princípios de hidrologia florestal para o manejo de bacias hidrográficas. São Paulo:ESALQ, 1986. 242 p.

LOCH, C. Topografia contemporânea: planimetria. 2. ed. Florianópolis: Ed. da UFSC, 2000.

MARBLE, D.F.; PEUQUET, D.J. Geographic Information Systems and Remote Sensing in MARBLE, D.F.; PEUQUET, D.J. (eds) Manual of Remote Sensing. American Society of Photogrammetry. Chapter 22, vol.1. (1983).

MASSITA, Aryhane; SEYDELL, Maria Rachel Russo. Usos e Aplicações da Estação Total Subsídios para a pesquisa e o ensino de topografia In: XIV Encontro de Iniciação Científica da PUC- Campinas, 16., 2009. Anais Campinas.Ed. PUC, 2009. Disponivel em:<http:/www.puccampinas.edu.br/websist/portal/pesquisa/ic/pic2009/resumo/2009823_221942_207316060_resB05.pdf> Acesso 25 mai. 2014.

PARADA, M. O. Elementos de Topografia - Manual Prático e Teórico de Medição e Demarcações de Terras; Edição do Autor, Impresso por Nagy e Filhos Ltda Artes Gráficas; 2ªed; São Paulo; 1992.

PISSARRA, T. C. T. Avaliação quantitativa das características geomorfológicas de microbacias hidrográficas $1^{\circ}$ ordem de magnitude em quatro posições do sistema natural de drenagem. 1998. 124 f. Dissertação (Mestrado em Produção Vegetal) - Faculdade de Ciências Agrárias e Veterinárias, Universidade Estadual Paulista, Jaboticabal, 1998.

PISSARRA, T. C. T.; POLITANO, W.; FERRAUDO, A. S. Avaliação de características morfométricas na relação solo-superfície da bacia hidrográfica do Córrego Rico, Jaboticabal (SP). Revista Brasileira de Ciência do Solo, Viçosa, v. 28, n.2, p. 297- 305, 2004.

PRUSKI, F. F. AMORIM, R. S. S.; SILVA, D. D.;GRIEBELER ,N. P.;SILVA ,J. M.A. Conservação de solo e água: praticas mecânicas para o controle da erosão hídrica. viçosa: Universidade Federal de Viçosa, 2006. 240 p.

RANIERI,S. B. L. Avaliação de métodos e escalas de trabalho para determinação de risco de erosão em bacia hidrográfica utilizando Sistemas de Informação Geográficas (SIG). 1996. 128 f. Dissertação (Mestrado em Engenharia) - Escola de Engenharia de São Carlos, Universidade de São Paulo, São Carlos, 1996.

REDENTE, E. F. et al. Manipulation of vegetation community dynamics for degraded land rehabilitation. In: SIMPÓSIO BRASILEIRO DE PESQUISA FLORESTAL, 1., 1993, Viçosa. Anais Viçosa: Sociedade de Investigações Florestais, 1993.

REIS, A.; ZAMBONIN, R. M.; NAKAZONO, E. M. Recuperação de florestas degradadas utilizando a sucessão e as interações planta-animal. São Paulo: Conselho Nacional da Reserva da Biosfera da Mata Atlântica, 1999. Caderno n. 14.

RIBEIRO, F. L. Mapa de vulnerabilidade à erosão da região do Alto Rio Pardo - Pardinho (SP). 2002. 119 f. Tese (Doutorado em Agronomia) - Faculdade de Ciências Agronômicas, Universidade Estadual Paulista Júlio de Mesquita Filho, Botucatu, 2002.

SILVA, A. T.; ROLIM, F. C. Neto; FRANÇA, M. V.; BOTELHO, F. J. L.; COELHO, J. M. J. Levantamento Topográfico com GPS Geodésico e Estação Total da Propriedade Embrapa Caprinos em Sobral - CE. Recife: Departamento de Tecnologia Rural da UFRPE, 2009.

STODULSKI, Leocir. Manual de Aprovação de Loteamentos. 2006. Monografia (Graduação) Curso de Engenharia Civil, União Dinâmica das Cataratas. Foz do Iguaçu. Disponível 
em:<http://pt.scribd.com/doc/75409502/11/LEVANTAMENTO-TOPOGRAFICOCADASTRAL\#page=19 >. Acesso em: 18 mai. 2014.

TEIXEIRA, A. L. A.; MORRETTI, E.; CHRISTOFOLETTI, A. Introdução aos sistemas de informação geográfica. Rio Claro:.Edição do Autor.1992. 80 p.

TESTONI, A. J. A importância da topografia na recuperação de áreas degradadas. Unoesc \& Ciência - ACET, Joaçaba, v. 1, n. 1, p. 21-30, jan./jun. 2010 